\title{
Battle to degas deadly lakes continues
}

\author{
Funding shortage is biggest hurdle for those striving to disarm three rare but lethal geological hazards.
}

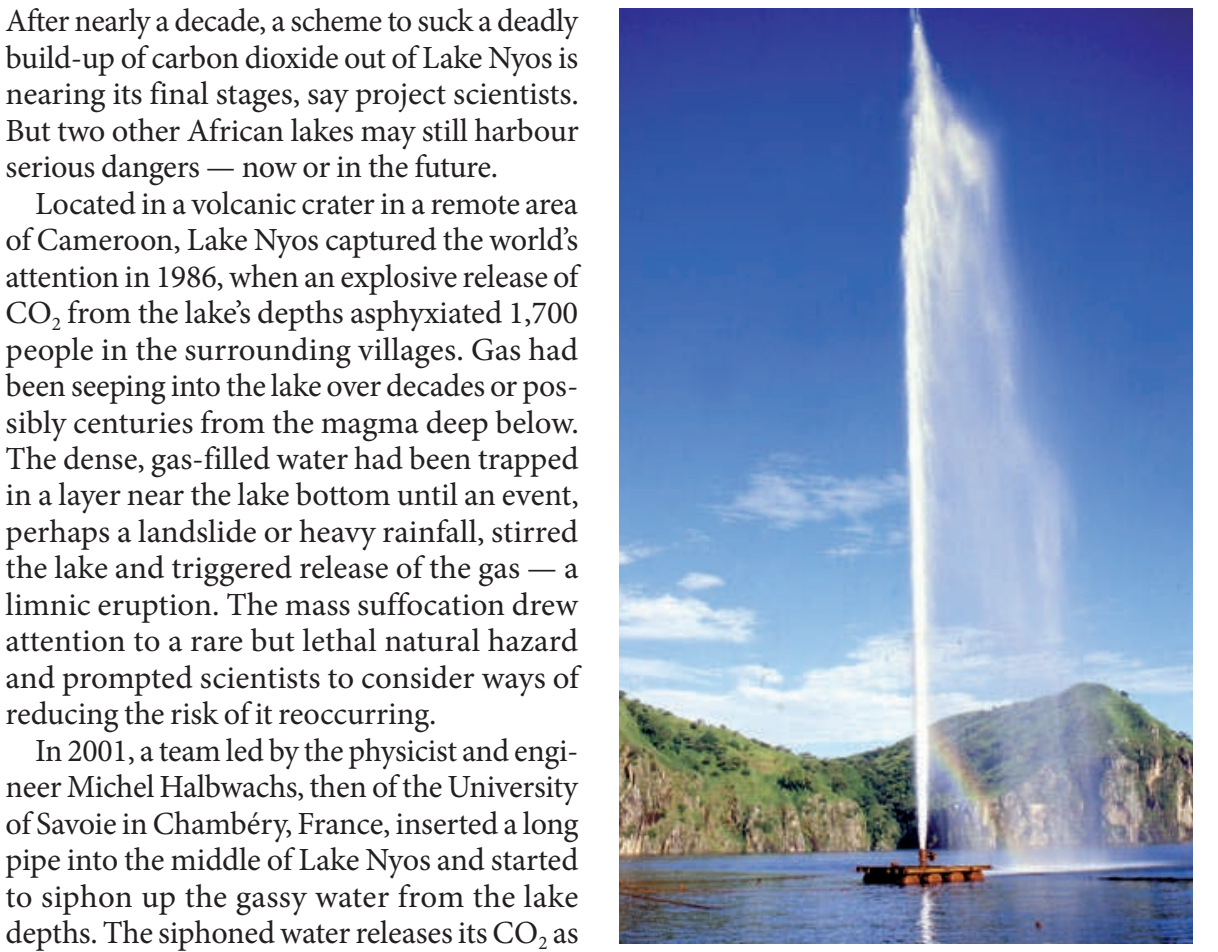

depths. The siphoned water releases its $\mathrm{CO}_{2}$ as pipe, then falls harmlessly back onto the lake. In this way, the size of the gas-charged layer below and the risk it poses steadily decrease.

Despite setbacks, the basic strategy is working, says Halbwachs, who is now head of the gas-extraction company Data Environnement, based in Chambéry. But one pipe makes for a slow extraction, leaving villagers at risk. The plan called for more pipes to be installed, but funds were not forthcoming. After campaigning for more than a decade, Halbwachs says that he has secured donations of $€ 1.4$ million (US\$1.8 million) from the United Nations Development Programme for two more pipes, which he hopes to deploy in Lake Nyos between November 2010 and February 2011. "The long delay is normal with international donors," says Halbwachs, who estimates that new pipes should make the region around Lake Nyos safe from a limnic eruption within 5 years.

"This is a big success story," says George Kling, a biogeochemist at the University of Michigan in Ann Arbor who has been studying the lake for decades. But he worries that the schedule may slip again. "I've heard lots of dates before about when the pipes are actually going in," he says. "For the sake of the people there, I hope something gets done sooner rather than later." of siphoning have effectively eliminated the separation of the lake's waters into layers, new gas entering from the lake bed could mix into a $\frac{a}{s}$ larger volume of water than before. According to Kling, it is harder to deal with more gas at a lower concentration because the gas pressure is insufficient to drive water up the pipes.

Takeshi Ohba, a geochemist at Tokai University in Hiratsuka, Japan, is in the process of securing more than $\$ 4$ million, half from the Japan Science and Technology Agency and half from the Japan International Cooperation Agency, to help create a more permanent solution for Lake Monoun. His team plans to visit the area in February 2011 to help train local scientists and develop a pump that can extract the gassy bottom waters.

The problems are different at Lake Kivu, which borders Rwanda and the Democratic Republic of the Congo. Lake Kivu's deep waters hold $\mathrm{CO}_{2}$ and methane. Several commercial projects are under way to extract the methane and turn it into energy (see Nature 460, 321323; 2009). So far, one 4-megawatt power plant is up and running. A 3.6-megawatt plant, which Halbwachs is heading up, has been rebuilt after the first collection platform sank in 2008. This plant was trialled successfully in June this year but is not yet in operation. Both are small demonstration projects compared with what may come: several hundred-megawatt-scale plants are being planned.

Most of Lake Kivu is relatively stable, with the gas-rich waters sitting below 330 metres. But local regulations are urgently needed, says Kling, to ensure that the degassed water from the planned full-scale power plants is returned to the lake at places where it won't stir up the deep layers, increasing the risk of eruption. Care must also be taken not to threaten the resident fish - an important local food source - by disturbing nutrient and oxygen levels.

A far greater threat lurks in the Gulf of Kabuno, which is connected to Lake Kivu by a narrow strait and holds a dangerous amount of gas just 12 metres below its surface. The World

Bank has pledged $\$ 3$ million to degas the gulf, but Halbwachs says his company would need perhaps $\$ 2$ million more before work could start. "It contains ten times more carbon dioxide than Nyos and is located in a very populated area," says Halbwachs.

Nicola Jones 